\title{
Prevalence of peripheral arterial disease among diabetic patients in Santo Domingo, Dominican Republic and associated risk factors
}

\author{
Stephanie Gonzalez Mejias ${ }^{1}$, Kamleshun Ramphul²
}

\begin{abstract}
${ }^{1}$ Treatment Unit, National Institute of Diabetes affiliated to the University Iberoamericana UNIBE, Santo Domingo, Dominican Republic ${ }^{2}$ Shanghai Xin Hua Hospital affiliated to the Shanghai Jiao Tong University, School of Medicine, Shanghai, China
\end{abstract}

Submitted: 15 January 2018

Accepted: 31 January 2018

Arch Med Sci Atheroscler Dis 2018; 3: e35-e40

DOI: https://doi.org/10.5114/amsad.2018.73527

Copyright $\odot 2018$ Termedia \& Banach

\section{Abstract}

Introduction: Peripheral arterial disease (PAD) is a major risk factor of coronary artery disease and a major complication of atherosclerosis. Peripheral arterial disease can be diagnosed with simple and low cost techniques. There are major risk factors of PAD that have been studied for different countries. However, no such study has been done for the Dominican Republic. We conducted a cross-sectional study to determine the prevalence of PAD and the risk factors among patients with diabetes in Santo Domingo, Dominican Republic.

Material and methods: Six hundred randomly chosen patients with previously diagnosed diabetes were enrolled in our study. Their blood pressure and ankle brachial index were calculated and a questionnaire was provided to gather information regarding gender, age, weight, ethnicity, known duration of diabetes along with any history of smoking, hypertension and hyperlipidemia. A physical examination was also done to assess for any active diabetic ulcers, previous foot ulcers and non-traumatic amputation. A microfilament test was conducted to check for peripheral neuropathy.

Results: Eighty-four diabetic patients were diagnosed with PAD with a prevalence of $14 \%$ in Santo Domingo, Dominican Republic. Statistically significant associations $(p<0.05)$ was found for female gender, presence of active foot ulcers, history of past foot ulcer, non-traumatic amputation, hypertension, hyperlipidemia and peripheral neuropathy. Glycated hemoglobin $\left(\mathrm{HbA}_{1 \mathrm{c}}\right)$, age and smoking were not statistically significant in our study.

Conclusions: Diabetic patients who are either female, have active foot ulcers, a history of past foot ulcer, non-traumatic amputation, hypertension, hyperlipidemia or peripheral neuropathy are more at risk of developing PAD.

Key words: risk factors, diabetes, peripheral arterial disease, Dominican Republic, Santo Domingo.

\section{Introduction}

According to the World Health Organization, cardiovascular disease is the number one cause of death in the island of the Dominican Republic [1]. There is a constant rise in the prevalence and the economic burden attributed to it keeps increasing. The epidemiologic data on the prevalence and risk factors of cardiovascular disease in the Dominican

\author{
Corresponding author: \\ Stephanie Gonzalez Mejias \\ Treatment Unit \\ National Institute of \\ Diabetes affiliated \\ the University \\ Iberoamericana UNIBE \\ Francia Avenue No. 129 \\ Gazcue Santo \\ 10203 Domingo \\ Dominican Republic \\ Phone: +1 (809) 689-4111 \\ Fax: +1 (809) 731-290 \\ E-mail: sgm.rk.md@gmail.com
}


Republic are very limited and this is in part due to the lack of proper funds and diagnostic tools. Hyperlipidemia, smoking, hypertension, diabetes and peripheral arterial disease (PAD) are the five main risk factors for cardiovascular diseases [2-5].

Peripheral arterial disease is an atherosclerotic vascular disease precipitated by the obstruction of a peripheral arterial vessel that results in ischemia $[6,7]$. Patients usually present with intermittent claudication [8] and there are an estimated 8-10 million people in the USA $[9,10]$ and 202 million worldwide who suffer from PAD [11]. One of the major risk factors for cardiovascular disease is diabetes, and the prevalence of PAD in patients with diabetes mellitus (DM) has been found to be between $10 \%$ and $42 \%$ [12, 13], higher than the prevalence in non-diabetics, which can vary between $3 \%$ and $20 \%$ [14-19].

The prevalence of PAD in the Dominican Republic has never been studied extensively, especially in diabetic patients. Peripheral arterial disease can be diagnosed in an out-patient setting using low cost equipment by measuring the ankle brachial index (ABI). The $A B I$ is sensitive and specific to the detection of atherosclerosis in the lower extremity vessels [20-23], making it an ideal tool in terms of cost and availability to assess the perfusion of the lower extremities. One third of the patients suffering from PAD are asymptomatic and despite its high prevalence, PAD can go undiagnosed by many doctors [24].

The aim of our study is to determine the prevalence of PAD in the Dominican Republic and the associated risk factors.

\section{Material and methods}

A cross sectional study was carried out on diabetic patients over the age of 18 who attended the out-patient clinic at the National Institute of Diabetes affiliated to the University Iberoamericana UNIBE of the Dominican Republic in Santo Domingo, Dominican Republic between July 2017 and December 2017. Two volunteers were trained to help collect our data and the physicians, nurses as well as medical students at the hospital provided assistance.

Diabetic patients attending the clinic were randomly selected and a questionnaire was provided. Out of the 634 who participated, 600 results were properly recorded and considered for our study. The patients were interviewed by the volunteers, who also helped them fill in the questionnaires. Age, gender, ethnic group, duration of DM, presence of active diabetic foot ulcers, history of past diabetic foot ulcers and non-traumatic amputations, and history of smoking, hypertension, hyperlipidemia were all recorded. Any recall bias was avoided by cross-checking the data with the pa- tient's file and previous visits. Results of the most resent glycated hemoglobin $\left(\mathrm{HbA}_{1 c}\right)$ and lipid profile within the last 6 months were also recorded.

The patients were asked to have a 5-10 min rest in the supine position and their blood pressure (BP) was recorded with a mercury sphygmomanometer. Two blood pressure measurements were recorded on each arm and the average on each side was calculated. If the difference between the two systolic BP measurements was greater than $10 \mathrm{~mm} \mathrm{Hg}$, a third recording was done.

Ankle pressures were recorded using a standardized sphygmomanometer and a Doppler ultrasonic device to accentuate the sounds over the posterior tibial and dorsalis pedis arteries.

The ankle brachial index (ABI) was calculated by dividing the average of the higher reading of the ankle pressure of the dorsalis pedis or posterior tibial artery by the average of the brachial systolic pressure of the same side [25]. Peripheral arterial disease was diagnosed if $A B I<0.9$, while $A B I>0.9$ showed absence of the disease. The $A B I>1.3$ suggested possible medial arterial calcification causing partial incompressibility of the arteries.

The physicians also performed a neurological evaluation of the foot using a $10 \mathrm{~g}$ microfilament to test over four plantar sites for both feet as recommended by the Lower Extremity Amputation prevention program and others [26-29]. The patients were asked to say "yes" when they felt the microfilament. The presence of peripheral neuropathy was also recorded in the patients if the patients failed to say yes to at least 2 of the four spots.

\section{Ethics clearance}

The study was reviewed and approved by the Ethics Committee of the National Institute of Diabetes affiliated to the University Iberoamericana UNIBE.

\section{Statistical analysis}

The data were analyzed using SPSS version 24.0 (SPSS Inc, Chicago, Illinois, USA) for Windows. The $\chi^{2}$ test was used to analyze for associations between categorical variables and Student's t test was used for continuous variables. Statistical significance was set at $p \leq 0.05$.

\section{Results}

Our study consisted of 600 diabetic patients evenly distributed between 300 males and 300 females, 591 of whom suffered from type II DM (98.5\%) and 9 from type I DM. The mean age of the patients was $60.62 \pm 8.35$ years with a mean duration of diabetes of $11.77 \pm 9.25$ years.

Twenty-nine patients (20 males and 9 females) had a history of non-traumatic amputation (4.8\%) 
and it was statistically significant $(p<0.05)$. Forty-three had active foot ulcers (7.2\%), among whom 31 were male and 12 were female, whereas 55 (9.2\%) patients had a prior history of diabetic foot ulcers (36 male, 19 female) and both were statistically significant $(p<0.05)$.

The prevalence of PAD was $14 \%$ (patients with $A B I \leq 0.9)$ and out of the 514 patients with $A B I$ $>0.9,48$ had an $A B I \geq 1.3$, signifying the possible presence of medial calcification. Fifty-two females and 32 males were diagnosed with PAD and there was a statistically significant association between PAD and female gender $(p<0.05)$. The prevalence of PAD in Hispanic Dominican diabetics was $16.8 \%$, in Black Dominican diabetics $15.4 \%$ and in white Dominicans diabetics $10 \%$, and no statistically significant association was found between the ethnic group and PAD. Thirty-two patients were active smokers (5.3\%) and 171 were ex-smokers (28.5\%). Twenty-five patients with a current or prior history of smoking were diagnosed with PAD while 59 nonsmokers were diagnosed but the difference was not statistically significant. A statistically significant association between PAD and hyperlipidemia was found with 78 patients having hyperlipidemia being diagnosed with PAD whereas only 6 were found to have PAD and a normal lipid profile. Fifty-five patients had both PAD and hypertension and 45 patients had both peripheral neuropathy and PAD and both risk factors were found to be statistically significant $(p<0.05)$.

The $\mathrm{HbA}_{1 \mathrm{c}}$ among patients with PAD was 9.11 \pm 2.43 and $8.22 \pm 2.42$ in patients without PAD and no statistical significance was found. The body mass index (BMI) of our study sample was 33.54 $\pm 7.21 \mathrm{~kg} / \mathrm{m}^{2}$. The results are shown in Tables I and II.

\section{Discussion}

This study is the first major study done for the island of the Dominican Republic to assess the prevalence of PAD in the diabetic population. The calculated prevalence of $14 \%$ is comparable to other studies, which varied mostly from $10 \%$ to $15 \%[12,13]$. The prevalence of PAD was lower in White Dominicans than Hispanic and Blacks, but there was no statistical significance unlike previous studies [30].

In our study we found that female gender, presence of active foot ulcer, history of previous diabetic foot ulcer, non-traumatic amputations, hypertension, hyperlipidemia and presence of peripheral neuropathy were statistically proven risk factors of PAD. There are several studies that have found a similar pattern among female gender [31-34], one possible reason being the higher life expectancy of females compared to males in the Dominican Republic [35].
Smoking is strongly associated with PAD in the general population. Our study showed no significant association between PAD and smoking, which was also found in other studies [12]. The recent educational campaigns to encourage diabetics to quit smoking could have been one reason for this finding in the Dominican Republic.

A statistically strong relationship between hypertension and hyperlipidemia was found in our study and this is coherent with other studies $[12,13,36] .53 .6 \%$ of the patients with PAD were found to have peripheral neuropathy in our study and it was statistically significant, suggesting that the presence of peripheral neuropathy increases the risk of future PAD in patients. Early detection of peripheral neuropathy can also serve to evaluate patients for underlying PAD in the future.

Table I. Demographics and prevalence of different conditions

\begin{tabular}{|c|c|}
\hline Parameters $(n=600)$ & $\begin{array}{l}\text { Values/range } \\
\text { of values }\end{array}$ \\
\hline \multicolumn{2}{|l|}{ Gender: } \\
\hline Male & 300 \\
\hline Female & 300 \\
\hline $\mathrm{BMI}\left[\mathrm{kg} / \mathrm{m}^{2}\right]$ & $33.54 \pm 7.21$ \\
\hline \multicolumn{2}{|l|}{ Ethnicity: } \\
\hline Hispanic & 482 \\
\hline Black & 73 \\
\hline White & 45 \\
\hline \multicolumn{2}{|l|}{ Age [years]: } \\
\hline Mean age of patients overall & $60.62 \pm 8.35$ \\
\hline Mean age of patients with PAD & $62.20 \pm 9.34$ \\
\hline Mean age of patients without PAD & $60.55 \pm 9.22$ \\
\hline Mean known duration of diabetes & $11.77 \pm 9.25$ \\
\hline Prevalence of type $1 \mathrm{DM}$ & 9 \\
\hline Prevalence of type $2 \mathrm{DM}$ & 591 \\
\hline \multicolumn{2}{|l|}{ Smoking: } \\
\hline Current smoker & 32 \\
\hline Ex-smoker who stopped & 171 \\
\hline Non-smokers & 397 \\
\hline Prevalence of hypertension & $498(83 \%)$ \\
\hline Prevalence of dyslipidemia & $348(58 \%)$ \\
\hline $\begin{array}{l}\text { Prevalence of peripheral artery } \\
\text { disease } A B \mid<0.9 \text { (PAD) }\end{array}$ & 84 \\
\hline
\end{tabular}

$P A D$ - peripheral arterial disease, $B M I$ - body mass index, DM diabetes mellitus, $A B I$ - ankle brachial index. 
Table II. Association between risk factors and peripheral arterial disease in patients with diabetes mellitus in Santo Domingo, Dominican Republic

\begin{tabular}{|c|c|c|c|}
\hline \multirow[t]{2}{*}{ Risk factors } & \multicolumn{2}{|c|}{ Prevalence of risk factors } & \multirow[t]{2}{*}{$P$-value } \\
\hline & No PAD $(n=516)$ & $\operatorname{PAD}(n=84)$ & \\
\hline Age & $60.55 \pm 9.22$ & $62.2 \pm 9.34$ & Not significant \\
\hline \multicolumn{4}{|l|}{ Gender: } \\
\hline Female & 248 & 52 & 0.018617 \\
\hline Male & 268 & 32 & \\
\hline \multicolumn{4}{|l|}{ Ethnic group: } \\
\hline Hispanic & 428 & 72 & Not significant \\
\hline Black & 52 & 8 & \\
\hline White & 36 & 4 & \\
\hline $\mathrm{HbA}_{1 \mathrm{c}}$ & $8.22 \pm 2.42$ & $9.11 \pm 2.43$ & Not significant \\
\hline \multicolumn{4}{|c|}{ Presence of active foot ulcers $(n=43)$ : } \\
\hline Yes & 28 & 15 & 0.000042 \\
\hline No & 488 & 69 & \\
\hline \multicolumn{4}{|c|}{ History of past foot ulcer $(n=55)$ : } \\
\hline Yes & 37 & 18 & 0.000027 \\
\hline No & 479 & 66 & \\
\hline \multicolumn{4}{|c|}{ Non-traumatic amputation: } \\
\hline Yes & 20 & 9 & 0.006728 \\
\hline No & 496 & 75 & \\
\hline \multicolumn{4}{|l|}{ Smoking: } \\
\hline Current/ex-smoker & 178 & 25 & Not significant \\
\hline Non-smoker & 358 & 59 & \\
\hline \multicolumn{4}{|l|}{ Hyperlipidemia: } \\
\hline Yes & 270 & 78 & $<0.00001$ \\
\hline No & 244 & 6 & \\
\hline \multicolumn{4}{|l|}{ Hypertension: } \\
\hline Yes & 443 & 55 & $<0.00001$ \\
\hline No & 73 & 29 & \\
\hline \multicolumn{4}{|l|}{ Peripheral neuropathy: } \\
\hline Yes & 197 & 45 & 0.007654 \\
\hline No & 319 & 39 & \\
\hline
\end{tabular}

PAD - peripheral arterial disease.

Our study was done in Santo Domingo but not all of our patients lived in the city all their life. The major limitation was the small sample size of 600 patients and being restricted to one city only. The results of the $\mathrm{HbA}_{1 \mathrm{c}}$ and the lipid profile were obtained from the patients' records over the last 6 months.
In conclusion, the prevalence of PAD in Santo Domingo, Dominican Republic was 14\% among diabetic patients. The prevalence was slightly higher in Hispanic Dominicans and Black Dominicans compared to White Dominicans but it was not statistically significant. Statistically significant associations with PAD were found for female gender, 
presence of active foot ulcers, history of past foot ulcers, non-traumatic amputations, hyperlipidemia, hypertension and peripheral neuropathy. No significant association was found with smoking, age, $\mathrm{HbA}_{1 \mathrm{c}}$ levels and ethnic groups.

\section{Conflict of interest}

The authors declare no conflict of interest.

\section{References}

1. Available at: http://www.who.int/gho/countries/dom. pdf?ua $=1$.

2. Carbayo JA, Divison JA, Escribano J, et al. Using anklebrachial index to detect peripheral arterial disease: prevalence and associated risk factors in a random population sample. Nutr Metabol Cardiovasc Dis 2007; 17: 41-9.

3. Ruiz-Canela M, Martinez-Gonzalez MA. Lifestyle and dietary risk factors for peripheral artery disease. Circ J 2014; 78: 553-9.

4. Fowkes FG, Murray GD, Butcher I, et al. Ankle brachial index combined with Framingham Risk Score to predict cardiovascular events and mortality: a meta-analysis. JAMA 2008; 300: 197-208.

5. Pang XH, Han J, Ye WL, Sun X. Lower extremity peripheral arterial disease is an independent predictor of coronary heart disease and stroke risks in patients with type 2 diabetes mellitus in China. Int J Endocrinol 2017; 2017: 9620513.

6. Weiner SD, Reis ED, Kerstein MD. Peripheral arterial disease. Medical management in primary care practice. Geriatrics 2001; 56: 20-2, 5-6, 9-30.

7. Mohler ER $3^{\text {rd }}$. Peripheral arterial disease: identification and implications. Arch Int Med 2003; 163: 2306-14.

8. Novo S. Classification, epidemiology, risk factors, and natural history of peripheral arterial disease. Diabetes Obes Metabol 2002; 4 Suppl 2: S1-6.

9. Writing Committee M, Gerhard-Herman MD, Gornik HL, Barrett C, Barshes NR, Corriere MA, et al. 2016 AHA/ACC Guideline on the Management of Patients With Lower Extremity Peripheral Artery Disease: Executive Summary. A Report of the American College of Cardiology/ American Heart Association Task Force on Clinical Practice Guidelines. Circulation 2017; 135: e686-725.

10. Selvin E, Erlinger TP. Prevalence of and risk factors for peripheral arterial disease in the United States: results from the National Health and Nutrition Examination Survey, 1999-2000. Circulation 2004; 110: 738-43.

11. Guo X, Li J, Pang W, et al. Sensitivity and specificity of ankle-brachial index for detecting angiographic stenosis of peripheral arteries. Circ J 2008; 72: 605-10.

12. Tseng $\mathrm{CH}$. Prevalence and risk factors of peripheral arterial obstructive disease in Taiwanese type 2 diabetic patients. Angiology 2003; 54: 331-8.

13. Janka HU, Standl E, Mehnert H. Peripheral vascular disease in diabetes mellitus and its relation to cardiovascular risk factors: screening with the Doppler ultrasonic technique. Diabetes Care 1980; 3: 207-13.

14. Meijer WT, Hoes AW, Rutgers D, Bots ML, Hofman A, Grobbee DE. Peripheral arterial disease in the elderly: the Rotterdam Study. Arterioscler Thromb Vasc Biol 1998; 18: 185-92.

15. Criqui MH, Fronek A, Barrett-Connor E, Klauber MR, Gabriel S, Goodman D. The prevalence of peripheral arte- rial disease in a defined population. Circulation 1985; 71: 510-5.

16. Mostaza JM, Manzano L, Suarez C, et al. Different prognostic value of silent peripheral artery disease in type 2 diabetic and non-diabetic subjects with stable cardiovascular disease. Atherosclerosis 2011; 214: 191-5.

17. Fan LC, Chen MY, Huang WC, et al. Pulse pressure and Michigan Neuropathy Screening Instrument are independently associated with asymptomatic peripheral arterial disease among type 2 diabetes community residents: a community-based screening program in Taiwan. Biomed J 2013; 36: 282-8.

18. Brito-Zurita OR, Ortega-Lopez S, Lopez del CastilloSanchez D, Vazquez-Tellez AR, Ornelas-Aguirre JM. Ankle-brachial index associated with diabetic foot: case-control study. Cirugia y Cirujanos 2013; 81: 131-7.

19. Brownrigg JR, Schaper NC, Hinchliffe RJ. Diagnosis and assessment of peripheral arterial disease in the diabetic foot. Diabet Med 2015; 32: 738-47.

20. Norgren L, Hiatt WR, Dormandy JA, Nehler MR, Harris KA, Fowkes FG. Inter-Society Consensus for the Management of Peripheral Arterial Disease (TASC II). J Vasc Surg 2007; 45 Suppl S: S5-67.

21. Zheng ZJ, Sharrett AR, Chambless LE, et al. Associations of ankle-brachial index with clinical coronary heart disease, stroke and preclinical carotid and popliteal atherosclerosis: the Atherosclerosis Risk in Communities (ARIC) Study. Atherosclerosis 1997; 131: 115-25.

22. Resnick HE, Lindsay RS, McDermott MM, et al. Relationship of high and low ankle brachial index to all-cause and cardiovascular disease mortality: the Strong Heart Study. Circulation 2004; 109: 733-9.

23. Dachun X, Jue L, Liling Z, et al. Sensitivity and specificity of the ankle: brachial index to diagnose peripheral artery disease: a structured review. Vasc Med (London, England) 2010; 15: 361-9.

24. Pearson T, Kukulka G, Ur Rahman Z. Ankle brachial index measurement in primary care setting: how long does it take? South Med J 2009; 102: 1106-10.

25. Peripheral arterial disease in people with diabetes. Diabetes Care 2003; 26: 3333-41.

26. Armstrong DG, Lavery LA, Harkless LB. Validation of a diabetic wound classification system. The contribution of depth, infection, and ischemia to risk of amputation. Diabetes Care 1998; 21: 855-9.

27. McNeely MJ, Boyko EJ, Ahroni JH, et al. The independent contributions of diabetic neuropathy and vasculopathy in foot ulceration. How great are the risks? Diabetes Care 1995; 18: 216-9.

28. Kumar S, Fernando DJ, Veves A, Knowles EA, Young MJ, Boulton AJ. Semmes-Weinstein monofilaments: a simple, effective and inexpensive screening device for identifying diabetic patients at risk of foot ulceration. Diabetes Res Clin Pract 1991; 13: 63-8.

29. Olmos PR, Cataland S, O'Dorisio TM, Casey CA, Smead WL, Simon SR. The Semmes-Weinstein monofilament as a potential predictor of foot ulceration in patients with noninsulin-dependent diabetes. Am J Med Sci 1995; 309: 76-82.

30. Collins TC, Petersen NJ, Suarez-Almazor M, Ashton CM. The prevalence of peripheral arterial disease in a racially diverse population. Arch Int Med 2003; 163: 1469-74.

31. Aboyans V, Criqui MH, McClelland RL, et al. Intrinsic contribution of gender and ethnicity to normal ankle-brachial index values: the Multi-Ethnic Study of Atherosclerosis (MESA). J Vasc Surg 2007; 45: 319-27.

32. Pradhan AD, Shrivastava S, Cook NR, Rifai N, Creager MA, Ridker PM. Symptomatic peripheral arterial dis- 
ease in women: nontraditional biomarkers of elevated risk. Circulation 2008; 117: 823-31.

33. Hiramoto JS, Katz R, Ix JH, et al. Sex differences in the prevalence and clinical outcomes of subclinical peripheral artery disease in the Health, Aging, and Body Composition (Health ABC) study. Vascular 2014; 22: 142-8.

34. McDermott MM. Sex differences in the ankle brachial index measurement and interpreting findings of sex differences in peripheral artery disease burden. Circ Cardiovasc Qual Outcomes 2016; 9 (2 Suppl 1): S5-7.

35. Available at: http://www.who.int/countries/dom/en/.

36. Poldermans D, Bax JJ, Kertai MD, et al. Statins are associated with a reduced incidence of perioperative mortality in patients undergoing major noncardiac vascular surgery. Circulation 2003; 107: 1848-51. 